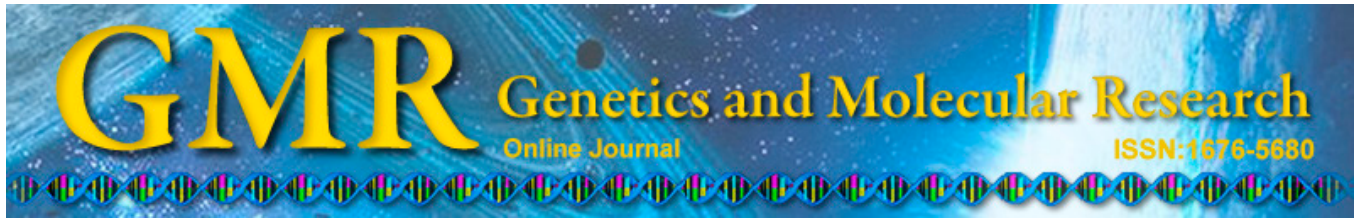

\title{
Evaluation of progenies from the fifth reciprocal recurrent selection cycle in maize
}

\author{
N.B. Alves, J.M.V. Pádua, K.O.G. Dias, R.P. Diniz, M.L. Guedes, \\ G.A. Cardoso and J.C. Souza \\ Department of Biology, Universidade Federal de Lavras, Lavras, MG, Brasil \\ Corresponding author: N.B. Alves \\ E-mail: natalia.b@hotmail.com
}

Genet. Mol. Res. 14 (3): 8236-8243 (2015)

Received September 16, 2014

Accepted February 20, 2015

Published July 27, 2015

DOI http://dx.doi.org/10.4238/2015.July.27.11

\begin{abstract}
The objective of this study was to evaluate the performance of 119 full sib progenies of the fifth cycle of reciprocal recurrent selection (RRS) derived from of Universidade Federal de Lavras maize breeding program. The experiment was carried out in an $11 \times 11$ triple lattice design at two locations (Lavras, Lambari). The plots consisted of two rows of $3 \mathrm{~m}$, with four plants per $1 \mathrm{~m}$ and 0.60 meters of spacing between lines. The grain yield was obtained as $\mathrm{kg} / \mathrm{plot}$ through weighing of husked ears. The contrast between progenies and controls was not significant, indicating there were no significant differences among the average grain yields of the progenies and controls. When considering the joint analysis, heritability was $64.2 \%$; however, this estimate did not differ from the values estimated for each location separately. Estimates of genetic and phenotypic variance among progenies ranged from 0.21 to 0.28 and 0.30 to 0.47 , respectively. Estimates of selection gain, for $10 \%$ selection intensity, indicated gains of $16 \%$ in the joint analysis of the two locations. The progenies of the fifth cycle of RRS had high average grain yield, associated with high variability. In comparison to the average grain yields exhibited by the controls, it was concluded that the progenies have the potential to be commercially exploited.
\end{abstract}

Key words: Zea mays L.; Reciprocal recurrent selection; Simple hybrid 


\section{INTRODUCTION}

One of the greatest contributions of science to society is the phenomenon of heterosis. Reciprocal recurrent selection (RRS) is one of a variety of techniques used to enhance heterosis in maize. RRS was originally proposed by Comstock et al. (1949) to improve the hybrid between two populations exploiting additive and non-additive effects. Furthermore, this method allows the improved populations to be sources of inbred lines, producing hybrids superior to those obtained from the original populations (Bértran and Hallauer, 1996; Hallauer et al., 2010). The main purpose of RRS is to genetically improve germplasm as a resource for breeding programs (Hallauer and Carena, 2012).

In RRS, two populations are evaluated in reciprocal crosses in which each population is used as tester for the other. In reciprocal crosses that present superior combining ability, the progenies of each population are selected and the genotypes are recombined to generate enhanced populations (Souza Jr., 2011), so that the evaluation is made among populations and recombination is done within each population, thereby maintaining the identity of each population. Therefore, in this type of process two types of progeny are required, one for evaluation (interpopulational) and the second for recombination (intrapopulational; Souza Jr., 2001). Therefore, improvement of the interpopulation hybrid depends on the improvement of heterosis between crossing of the populations as well as the improvement, per se, of the populations. However, in many situations it has been reported that these interpopulational selection methods have significantly increased the interpopulational hybrid response in one of the populations, with unsatisfactory response, or even a negative response, in another population (Souza Jr., 1999). For a more comprehensive discussion of RRS we suggest reading Hallauer et al. (2010) and Souza Jr. (2011).

In most cases, RRS was used in populations obtained from a large number of genitors, synthetics, varieties or compounds (Hallauer and Carena, 2012), thus, a pertinent question relates to the behavior of populations obtained from a few individuals. One option for obtaining these populations is the use of commercial single hybrids because they have the advantages of wide adaptability and high grain yield potential, since they are only recommended if they have high performance in a high number of environments. Allied to this, these hybrids are highly heterozygous, generating $\mathrm{S}_{0}$ populations with high genetic variability. Thus, two important aspects are associated with the choice of a population when seeking genetic enhancement, high average and genetic variability.

In order to verify the efficiency of a recurrent selection program one should determine the genetic progress of the selection periodically. In a few reports in this regard, considering populations from-single cross hybrids, satisfactory responses conducted with selection were observed (Raposo and Ramalho, 2004; Reis et al., 2014).

Within this context, the objective of the present study was to evaluate the performance of sib progenies of the fifth cycle of RRS of maize derived from the breeding program of Universidade Federal de Lavras (UFLA).

\section{MATERIAL AND METHODS}

The RRS program of UFLA began in 2003, employing a method similar to that proposed by Souza Jr. (1987). The choice of genitors was determined by a diallel in which they had a high specific and general combining ability. The two populations, named 1 and 2, are 
derived from two commercial single cross hybrids ( $\mathrm{SH}$ ), and were obtained by randomly intercrossing $3000 \mathrm{~F}_{1}$ plants of each $\mathrm{SH}$ in two isolated fields that generated two populations in Hardy-Weinberg equilibrium. For a more comprehensive discussion of the UFLA's RRS program we recommend reading Reis et al. (2013, 2014).

To evaluate the progenies of the fifth RRS cycle, initially, the seeds of the recombination units of two populations selected after evaluation of the fourth selection cycle were sown and intrapopulation recombination was conducted, which provided the two populations in cycle 5 (C5). Seeds of each of the two C5 populations were sown in alternate rows with $50 \mathrm{~cm}$ of spacing between rows in order to facilitate specific crosses to obtain full sib progeny and prolific plants. A total of 119 interpopulational full sib progenies were obtained, which were submitted for evaluation. The second ear was protected and self-pollinated to obtain the $\mathrm{S}_{1}$ progenies used as recombination units for the next cycle.

The full sib progenies, along with two commercial hybrids used as controls (P30F53 and GNZ 9501), were evaluated in an 11 x 11 triple lattice experimental design in two locations, Lavras and Lambari. The plots consisted of two 3-m rows with 12 plants per row, with four plants per $1 \mathrm{~m}$ and $0.60 \mathrm{~m}$ spacing between rows.

Grain yield was evaluated based on the husked ear weight per plot $(\mathrm{kg} / \mathrm{plot})$. The weight of the ears was corrected for the ideal stand using analysis of covariance and for grain moisture of $13 \%$.

First, individual analyses of variances were carried out based on the following model:

$$
y_{i j k}=u+t_{i}+b_{j(k)}+r_{k}+e_{i j k}
$$

where, $y_{i j k}$ is the observation regarding treatment $\mathrm{i}$ in block $\mathrm{j}$ within repetition $\mathrm{k}$; $u$ is the constant associated with the observations; $t_{i}$ is the random effect of treatment $\mathrm{i}$, where $\mathrm{i}=1$, $2,3 \ldots 121 ; b_{j(k)}$ is the random effect of block $\mathrm{j}$, in repetition $\mathrm{k}$, where $\mathrm{j}=1,2 \ldots 11 ; r_{k}$ is the fixed effect of repetition $\mathrm{k}$, where $\mathrm{k}=1,2,3$; and $e_{i j k}$ is the experimental error of the plot that received treatment $\mathrm{i}$ in block $\mathrm{j}$, in repetition $\mathrm{k}$, assuming that the errors are independent and normally distributed with average zero and $\sigma_{e}^{2}$.

In the joint analysis model for the locations, we used the adjusted mean considering the effect of treatment as random and the effect of location as fixed, according to the model below:

$$
y_{i s}=u+t_{i}+l_{s}+t l_{i s}+\bar{e}
$$

where, $y_{i s}$ is the observation regarding treatment $\mathrm{i}$, in location $\mathrm{s} ; u$ is the constant associated with the observations; $t_{i}$ is the effect of treatment $\mathrm{i}$, where $\mathrm{i}=1,2,3 \ldots 121 ; l_{s}$ is the effect of location $\mathrm{s}$, where $\mathrm{s}=1,2 ; t l_{i s}$ is the effect of the interaction between treatment $\mathrm{i}$ and environment s; and $\bar{e}$ is the average experimental error of individual analyzes at each location, assuming that the errors are independent and normally distributed with average zero and $\sigma_{e}^{2}$.

Genetic and phenotypic parameters for the grain yield were estimated from the expectations of mean squares using the method of moments. The confidence interval associated 
with the estimates of genetic and phenotypic variances of progenies was estimated using the following equation:

$$
C I=\left[\frac{n t \sigma^{2}}{\chi_{n t ; 0,975}^{2}} \leq \sigma^{2} \leq \frac{n t \sigma^{2}}{\chi_{n t ; 0,025}^{2}}\right]=0,95
$$

where, $C I$ is the confidence interval; $n t$ is the number of degrees of freedom associated with the estimation of genetic and phenotypic variances; $\hat{\sigma}^{2}$ is the estimate of genetic and phenotypic variances; and $\chi^{2}$ is the tabulated chi-square. The value of nt for progeny genetic variance in the joint analysis was obtained through the Satterthwaite method because in this case the estimate of the variance is obtained by linear combination of mean squares:

$$
n t=\frac{\left(M S_{p}-M S_{p l}\right)^{2}}{\frac{M S_{p}^{2}}{f 1}+\frac{M S_{p l}^{2}}{f 2}}
$$

where, $M S_{p}$ is the mean square of progenies; $M S_{p l}$ is the mean square of the progenies-location interaction; $f 1$ is the degrees of freedom of progenies; and $f 2$ is the degrees of freedom of the progenies-location interaction.

The broad sense heritability $\left(\widehat{h}^{2}\right)$ averages among progenies were estimated using the following expression:

$$
\widehat{h}^{2}=\frac{\sigma_{g}^{2}}{\sigma_{g}^{2}+\frac{\sigma_{e}^{2}}{r}}
$$

where, $\widehat{\sigma}_{g}^{2}$ is the estimate of the genetic variance of the joint analysis; $\widehat{\sigma}_{e}^{2}$ is the estimate of the variance of the error of the joint analysis; and $r$ is the number of repetitions.

The estimate of the error associated with heritability was obtained using the method proposed by Knapp et al. (1985). Estimates of the expected gain after progeny selection were also obtained. The expected gain was obtained by multiplying heritability by the selection differential.

The selection gain (SG) considering two different selection intensities (10 and 20\%) was estimated using the expression:

$$
S G=i x \frac{\hat{\sigma}_{g}^{2}}{\sqrt{\hat{\sigma}_{f}^{2}}}
$$


where, $i$ is the standardized selection differential; and $\widehat{\sigma}_{f}^{2}$ is the estimate of the phenotypic variance.

The error associated with the SG S was estimated using the expression presented by Bridges et al. (1991):

$$
S(S G)=\sqrt{\frac{2 i^{2}}{r}\left\{\left(\frac{M S_{p}^{2}}{D F_{1}}\right)\left[\left(1+\frac{M S_{E}}{M S_{p}}\right)^{2} / 4\right]+\frac{M S_{E}^{2}}{D F_{2}}\right\} / M S_{p} \quad \text { (Equation 7) }}
$$

where, $S(S G)_{\mathrm{G}}$ is the error associated with the gain expected with the selection; $M S_{p}$ is the mean square of the progeny; $D F$ is the degrees of freedom of the progeny; $M S_{E}$ is the mean squared error; and $D F_{2}$ is the degrees of freedom associated with the error.

The index of coincidence was estimated between locations and then comparing each location with the joint analysis using the estimator proposed by Hamblin and Zimmermann (1986):

$$
\mathrm{IC}_{\mathrm{i}}=\frac{\mathrm{A}-\mathrm{C}}{\mathrm{M}-\mathrm{C}}
$$

where, $C$ is the number of selected progenies in both locations due to chance. It is assumed that among the number of selected treatments, a proportion equal to the intensity of selection coincide by chance. Thus, if in 100 treatments it was decided to select $10 \%$ (or 10 individuals), $10 \%$ of 10 (or 1), will coincide due to chance; $A$ is the number of common treatments selected in both locations; $M$ is the number of treatments selected in one location.

All analyzes for this study were performed using the R software (R Development Core Team, 2014).

\section{RESULTS AND DISCUSSION}

The significance of the source of variation for the fixed effect of location indicates that location has a significant effect on grain yield, irrespective of the treatment condition (Table 1). The significant effect of progenies on grain yield demonstrates the existence of variability, a fact that is important because one of the basic principles for the success of recurrent selection is the maintenance of genetic variability over selection cycles. This also shows that there are differences in the complementarity between the crossings of the two populations. This is an important aspect because with it the selection of the best combinations can be performed, which is one of the assumptions of RRS.

The interaction between progenies and controls (Prog vs Test) was not significant, indicating no significant differences between the average grain yield of the progenies and the controls. Given that the controls correspond to commercial hybrids, it can be inferred that the progenies have the potential to generate hybrids that are able to compete in the maize market. 
Table 1. Summary of joint analysis of variance for grain yield ( $\mathrm{kg} / \mathrm{plot})$, for the two study locations of Lavras and Lambari, Brazil.

\begin{tabular}{lcc}
\hline SV & d.f. & MS \\
\hline Locations (L) & 1 & $9.9040^{* *}$ \\
Treatments (Trt) & $(120)$ & $1.8825^{* *}$ \\
Progenies (Prog) & 118 & $1.8076^{* *}$ \\
Among Controls (Test) & 1 & $12.3818^{* *}$ \\
Prog $v s$ Test & 1 & $0.2245^{\mathrm{NS}}$ \\
Trt $v s$ L & $(120)$ & $0.6469^{* *}$ \\
Prog $v s$ L & 118 & $0.5393^{* *}$ \\
Test $v$ L & 1 & $1.9685^{*}$ \\
(Prog $v s$ Test) $v s$ L & 1 & $0.0200^{\mathrm{NS}}$ \\
Error & 420 & 0.4050 \\
Overall average & 3.65 & \\
Progenies average & 4.10 & \\
Control average & 3.21 & \\
Selective accuracy & 0.80 & \\
\hline
\end{tabular}

$\mathrm{SV}=$ source of variation; d.f. $=$ degrees of freedom; $\mathrm{MS}=$ mean squares. ${ }^{*},{ }^{* *} \mathrm{~F}$ test significant at 1 and $5 \%$ probability, respectively.

There was a significant difference in the average performance of treatments, between locations, for grain yield (Table 1). Partitioning the sum of squares of the interaction between progenies and location shows that the grain yield of progenies was not consistent at both locations. The same was observed for the controls and location interaction, in which the controls exhibited different behavior between the two locations. However, the contrast between controls and progenies when accounting for location was not significant, indicating consistent behavior in both locations.

The experimental precision, obtained by selective accuracy (Resende and Duarte, 2007), was 0.80, which according to the criteria of these authors indicates high experimental precision. Importantly, to obtain reliable genetic and phenotypic parameter estimates, the accuracy with which the experiments are conducted is of fundamental importance. Broad sense heritability estimates obtained for each location and for both locations together were different from zero (Table 2). For the joint analysis, heritability was $64.2 \%$, but this estimate does not differ from the other estimates of heritability for each location. In previous cycles of the same populations evaluated in this study, estimates of smaller magnitudes were obtained, 29.8 and $51.5 \%$ for cycles zero and three, respectively (Reis et al., 2014). The increase in the magnitude of the heritability estimates in the cycle sequences presented here is indicative of the accumulation of favorable alleles in the populations, showing that reciprocal recurrent selection is an efficient method of improvement. These estimates are consistent with results found in the literature (Hallauer and Carena, 2012).

Table 2. Heritability estimates $\left(h^{2}\right)$ for the average grain yield of progenies, genetic variance $\left(\widehat{\sigma}_{\mathrm{g}}^{2}\right)$, phenotypic variance $\left(\hat{\sigma}_{\mathrm{f}}^{2}\right)$, and selection gain $(\mathrm{SG})$ for maize grown at two locations in Brazil and in the joint analysis between these two locations.

\begin{tabular}{|c|c|c|c|c|}
\hline & $\mathrm{h}^{2}(\%)$ & $\hat{\sigma}_{g}^{2}$ & & $\mathrm{SG}^{(2)}$ \\
\hline Lavras & $59.8(44.28-70.63)^{1}$ & $0.28(0.22-0.37)^{1}$ & $0.47(0.37-0.62)^{1}$ & $24( \pm 2)^{3}$ \\
\hline Lambari & $74.2(64.23-81.15)$ & $0.24(0.19-0.31)$ & $0.32(0.25-0.42)$ & $16( \pm 4)$ \\
\hline Joint & $64.2(51.60-72.89)$ & $0.21(0.15-0.31)$ & $0.30(0.23-0.39)$ & $16( \pm 8)$ \\
\hline
\end{tabular}

${ }^{1}$ Confidence intervals at $5 \%$ of probability; ${ }^{2} \mathrm{SG}=$ values presented in percentage (\%) and obtained considering a selection index (i) of $10 \% ;{ }^{3}$ standard error associated with the selection gain. 
Estimates of genetic and phenotypic variance among progenies ranged from 0.21 to 0.28 and 0.30 to 0.47 , respectively (Table 2). For these estimates, the lower limits were always positive, indicating that these components are different from zero. As with heritability estimates, what is expected in an RRS program is that the genetic variance estimates increase with advancing cycles, indicating an accumulation of favorable alleles. The comparison of these results with others found in the literature is not relevant due to the different units used.

SG estimates, for $10 \%$ selection intensity, indicate gains of $16 \%$ in the joint analysis of locations (Table 2). In studies conducted using the same populations with interpopulational hybrids of previous RRS cycles, gains under 14\% were reported (Reis et al., 2013, 2014). The results presented here corroborate those previously reported for heritability.

The comparison between SG estimates is not always very easy because there are differences in the experimental accuracy of assessments and regarding the selection intensity used. However, some inferences can be made in this regard. In the literature, there are reports of gain achieved with long term RRS with various selection cycles. In these cases, the average gain ranged from 7 to 13\% per cycle (Santos et al., 2007; Hallauer and Carena, 2012; Berilli et al., 2013), which is lower than the values reported in the present study.

Another fact related to the coincidence of the productive performance of progeny in both locations is the index of coincidence, obtained by considering the two locations (Lavras vs Lambari) and also considering the joint analysis (Lavras vs Joint and Lambari vs Joint; Table 3). Considering the selection intensity of $10 \%$, the coincidence between the two locations was very low $(16.7 \%)$; however, for the joint analysis, this value was higher $(58.3 \%)$. As expected, with a selection intensity of $20 \%$ there is a greater coincidence in all cases. With these results it is clear that to practice selection in one location, be it Lavras or Lambari, leads to significant losses in SG. Therefore, the best strategy is to make the selection using the average of the two locations, based on the results of the joint analysis.

Table 3. Estimates of the index of coincidence ( $\mathrm{IC}_{\mathrm{i}}$ ) of the best treatments selected, at different selection intensities, for maize progenies grown at two locations in Brazil and in the joint analysis between these two locations.

\begin{tabular}{lcc}
\hline & $\mathrm{IC}_{\mathrm{i}}(10 \%)$ & $\mathrm{IC}_{\mathrm{i}}(20 \%)$ \\
\hline Lavras $v s$ Lambari & $16.7 \%$ & $45.8 \%$ \\
Lavras $v$ Joint & $58.3 \%$ & $75 \%$ \\
Lambari $v s$ Joint & $58.3 \%$ & $75 \%$ \\
\hline
\end{tabular}

These results show that in the present study substantial progress can be made in the selection of hybrid populations derived from commercial single cross hybrids. It is noteworthy that as commercial hybrids perform well, the strategy of using these hybrids is interesting to plant breeding programs since it is possible to ally high average with variability to select in future cycles. In this context, the fifth cycle of RRS among full sib progenies succeeded in maintaining genetic variability and favorably increased the average grain yield.

In conclusion, the progenies of the fifth RRS cycle have high average grain yield associated with high variability. Compared with the averages presented for the controls, it was concluded that the progenies have the potential to be commercially exploited. 


\section{REFERENCES}

Berilli APCG, Pereira MG, Trindade RS, Costa FR, et al. (2013). Response to the selection in the 11th cycle of reciprocal recurrent selection among full-sib families of maize. Acta Sci. Agron. 35: 435-441.

Bértran FJ and Hallauer AR (1996). Hybrid improvement after reciprocal recurrent selection in BSSS and BSCB1 maize populations. Maydica 41: 25-33.

Bridges WC, Knapp SJ and Cornelius PL (1991). Standard errors and confidence interval estimators for expected selection response. Crop Sci. 31: 253-255.

Comstock RE, Robinson HF and Harvey PH (1949). A breeding procedure designed to make maximum use of both general and specific combining ability. Agron. J. 41: 360-367.

Hallauer AR and Carena MJ (2012). Recurrent selection methods to improve germplasm in maize. Maydica 57: 266-283. Hallauer AR, Carena MJ and Miranda Filho JB (2010). Quantitative Genetics in Maize Breeding. 3rd edn. Springer, New York. Hamblin J and Zimmermann MJO (1986). Breeding common bean for yield in mixtures. Plant Breed. Rev. 4: 245-272.

Knapp SJ, Stroup WW and Ross WM (1985). Exact confidence intervals for heritability on a progeny mean basis. Crop Sci. 25: 192-194.

R Development Core Team (2014). R: a language and environment for statistical computing. R Foundation for Statistical Computing, Vienna. Available at [http://www.R-project.org/]

Raposo FV and Ramalho MAP (2004). Componentes de variância genética de populações derivadas de híbridos simples de milho. Rev. Bras. Milho Sorgo 3: 402-413.

Reis MCD, Guedes FL, Abreu GB and de Souza JC (2013). Reciprocal recurrent selection in maize enhances heterosis and ears yield. Euphytica 191: 217-222.

Reis MC, Padua JM, Abreu GB, Guedes FL, et al. (2014). Estimates for genetic variance components in reciprocal recurrent selection in populations derived from maize single-cross hybrids. Sci. World J. 2014: Article ID 540152.

Resende MDV and Duarte JB (2007). Precisão e controle de qualidade em experimentos de avaliação de cultivares. Pesq. Agropec. Trop. 37: 182-194.

Santos MF, Camara TMM, Moro GV, Costa EFN, et al. (2007). Responses to selection and changes in combining ability after three cycles of a modified reciprocal recurrent selection in maize. Euphytica 157: 185-194.

Souza Jr CL (1987). Reciprocal recurrent selection with half-sib progenies obtained alternately from non-inbred (S0) and inbred (S1) plants in maize. Maydica 22: 19-31.

Souza Jr CL (1999). Recurrent selection and heterosis. In: Genetics and exploitation of heterosis in crops (Gerdes JT, Coors JG and Pandey S, eds). American Society of Agronomy, Madison, Wisconsin, 1-524.

Souza Jr CL (2001). Melhoramento de espécies alógamas. In: Recursos genéticos e melhoramento - plantas (Nass LL, Valois ACC, de Melo IS and Inglis MCV, eds.). Fundação-MT, Rondonópolis, 159-199.

Souza Jr CL (2011). Cultivar development of allogamous crops. Crop Breed. Appl. Biotechnol. 11: 8-15. 